\title{
O ACONSELHAMENTO TERAPÊUTICO NA ATUALIDADE
}

\author{
Yolanda CINTRÃo ForGhIERI
}

\begin{abstract}
Resumo: O Aconselhamento Terapêutico, também denominado Aconselhamento Psicológico, consiste num relacionamento inter-pessoal de ajuda existencial, cuja origem remonta a Antiguidade, na "cura pela palavra" introduzida e praticada pelo filósofo Empédocles e adotada por outros filósofos depois dele, e por médicos quando estes surgiram. Teve rápida evolução a partir do século XX, principalmente após cada uma das grandes guerras mundiais, quando passou a ser praticado por muitos orientadores educacionais, profissionais, e enfermeiras, para atenderem a necessidade de socorrer à numerosas pessoas abaladas existencialmente, para as quais a quantidade de psiquiatras e psicoterapeutas não era suficiente. A partir de 1950 foi reconhecido pela comunidade científica como um eficiente relacionamento interpessoal de ajuda terapêutica, próxima, mas diferente da psicoterapia. Passou, então, a ser influenciado por várias abordagens psicológicas, entre as quais a fenomenológica. Fundamentados nesta, são apresentados os fundamentos e a prática de Aconselhamento, que se constitui de dois momentos básicos: o envolvimento existencial e o distanciamento reflexivo, complementares e reciprocamente reversíveis.
\end{abstract}

Palavras-chave: Aconselhamento Terapêutico, Adoecimento Existencial, Abordagem Fenomenológica, Existência Humana.

\section{Introdução}

Vivemos em uma época na qual quase tudo na vida tornou-se mais acelerado, como se já não houvesse tempo para dar conta de tudo o que necessitamos fazer. Também as distâncias entre os vários lugares, desde duas cidades, estados e até países, tornaram-se de certo modo mais curtas, pois podemos alcançá-los bem mais rapidamente do que em outras épocas nas quais não dispúnhamos de helicópteros e aviões. E os acontecimentos de lugares distantes que antes demoravam dias ou meses para deles tomarmos conhecimento, hoje com os atuais meios de comunicação, eles nos são enviados quase instantaneamente. Em um único dia recebemos tantas informações e temos de fazer tantas coisas que precisamos correr no tempo para dar conta de todas, ou de quase todas. E quando nos encontramos muito contrariados, com algum abalo psicológico, nossas dificuldades para vencer o tempo ficam consideravelmente aumentadas. Por isso é muito importante que as terapias de perturbações psicológicas não sejam prolongadas, pois nossa vida decorre rapidamente.

Nesse panorama se insere o Aconselhamento Terapêutico (A.T.) que pretende ajudar pessoas que se encontram aflitas e agitadas, ou tristes e desanimadas, a recuperarem, de modo relativamente rápido, a chama de seu existir, a luz que volte a iluminar a 
caminhada de sua existência. Assim sendo, tal ajuda terapêutica não se propõe a lidar e curar os sintomas e psicopatologias, pois eles fazem parte da vida de todos nós, inclusive daqueles que são considerados normais e se propõem a ajudar seus semelhantes.

O A.T. pretende atingir, diretamente, os aspectos saudáveis dos clientes, que também fazem parte de nossa vida, mesmo na daqueles cujas perturbações psicológicas os obscurecem de algum modo.

Todos nós, seres humanos, estamos sujeitos a ficarmos abalados psicologicamente em momentos de extrema frustração e contrariedade. Quando, por exemplo, temos que nos defrontar com a morte de uma pessoa próxima e muito querida; ou com o seu lento definhar, sabendo que nada podemos fazer para salvá-la, sentimo-nos completamente impotentes; ou qualquer outra adversidade que nos atinja no mais íntimo de nosso ser.

Em decorrência de todas essas considerações, não há uma completa distinção e conseqüente separação entre o aconselhador e o cliente, pois em seu existir ambos possuem semelhanças básicas que os identificam de algum modo. Somos todos companheiros na difícil jornada que constitui a nossa existência, ora com alegrias e contentamentos, ora com tristezas e frustrações. As situações nas quais, cada um de nós experiencia tais sentimentos podem ser diferentes, mas as vivências são semelhantes. A diferença entre ambos encontra-se no fato de ser o aconselhador a pessoa que se dispõe a ajudar àquela que lhe pede ajuda, por estar vivenciando momentos difíceis que não está conseguindo enfrentar sozinha.

\section{Origem do Aconselhamento Terapêutico}

Desde tempos imemoriais, quando os seres humanos começaram a existir, e a se relacionar, teve início também, a ajuda que alguns passaram a prestar a seus semelhantes. Assim sendo, de um modo geral, o Aconselhamento sempre existiu e volta a assumir atualmente grande importância por ser uma relação de ajuda, de certo modo rápida, a pessoas que dela necessitam. Pois, como disse anteriormente, estamos todos vivendo uma época em que tudo decorre de modo cada vez mais acelerado.

Entretanto, desejando saber desde quando o A.T. poderia ser encontrado, procurei-o em textos de historiadores, onde verifiquei que por volta de 450 anos antes de Cristo, na Antiguidade, o filósofo Empédocles já recomendava o que denominou de "cura pela palavra". Esta consistia no tratamento de doentes através da conversação do filósofo com eles; as doenças podiam ser físicas ou psíquicas, pois ainda não eram feitas distinções entre ambas (Piñero \& Meseguer, 1970).

Depois de Empédocles, vários filósofos, tais como Platão e Aristóteles, e alguns médicos - a partir de Hipócrates - também recomendavam a conversação com a pessoa doente. O tipo de conversação variava, de acordo com os sintomas dos doentes e o posicionamento do filósofo ou do médico diante da doença.

Podia ser um diálogo amigável e acolhedor, com informações e esclarecimentos, conselhos e até normas a serem rigorosamente seguidas (Alexander \& Selesnick, 1968). 
Do século XX em diante, principalmente após as duas grandes guerras mundiais, houve um considerável aumento de pessoas com perturbações psicológicas, diante de uma pequena quantidade de profissionais considerados credenciados para tratá-las. Estes eram apenas alguns psiquiatras que fossem também psicanalistas. A partir dessa ocasião, diversos profissionais, principalmente enfermeiras e orientadores educacionais, por força das circunstâncias, passaram a prestar ajuda terapêutica a muitas daquelas pessoas, no decorrer de suas funções específicas. Deste modo o A.T. teve rápido e amplo desenvolvimento nos hospitais, nas escolas, assim como nas instituições de orientação e treinamento profissional, de serviço social e de higiene mental.

Entretanto, foi só a partir da década de 1950 que o A.T., também denominado de Aconselhamento Psicológico passou a ser reconhecido pela comunidade científica como uma eficiente forma de ajuda terapêutica, próxima, porém diferente da psicoterapia. O psicólogo americano Carl Rogers teve grande influência para que isso acontecesse, com a publicação de seu livro Counseling and Psychoterapy, em 1942. Desde então o Aconselhamento passou a ser influenciado pelas terapias de várias abordagens da personalidade, principalmente a rogeriana, a comportamental e a fenomenológica da qual trato nesta exposição.

\section{Quem Somos Nós}

\section{Minhas primeiras idéias}

Elas começaram a surgir muito cedo, desde a minha infância, no convívio com minha mãe. Eu era uma pessoa muito apegada a ela, a amava profundamente e não conseguia dela me afastar nem por algumas horas. Ela era muito dedicada a mim e aos meus irmãos e cuidava bem de si e dos afazeres domésticos. Entretanto, de tempos em tempos, ela sofria de períodos de crise, nos quais ficava muito agitada e angustiada. Andando de um lado para outro dizia estar desesperada, com medo de enlouquecer e de morrer, pois seu coração não resistiria a tanta aflição. Nessas ocasiões eu também ficava muito abalada, com pavor de que ela morresse de repente e me deixasse sozinha no mundo. Eu era muito triste, sem a alegre energia própria das crianças; era magra, abatida, sem apetite e com muita insônia, pois temia que ela morresse enquanto eu estivesse dormindo. Até que por volta dos meus 6 ou 7 anos, não agüentando mais tanto sofrimento, comecei a refletir como poderia melhorar aquela minha situação. Foi quando cheguei à conclusão que meu sofrimento deveria ser porque eu amava muito e só a minha mãe. Talvez me sentisse melhor se conseguisse amar a outra mulher que fosse gorda e saudável para me dar a segurança de que não iria morrer de repente. E foi assim que comecei a fazer o que hoje denomino de "exercício de amar as pessoas". A primeira escolhida foi tia Laura, que era gorda e corada, tinha apenas um filho e desejava muito ter uma filha; morava em Santos, mas vinha freqüentemente em minha casa em São Paulo. Então quando ela veio passar vários dias conosco, eu procurei me aproximar dela, conversando sobre a igreja, os santos que ela preferia, pois era muito religiosa. Eu ficava bem perto dela, 
ouvindo-a com atenção e abrindo-me para amá-la. Sua beleza, seu ar meigo e sua aparência saudável conquistaram-me rapidamente. E como era agradável amá-la sem o receio de que morresse de repente. Ela convidou-me para passar uns dias com ela em Santos e eu aceitei e fui. Pela primeira vez consegui me afastar de minha mãe. Uma deliciosa vivência de liberdade envolveu-me completamente e um enorme desejo de ampliar essa minha experiência. Dessa ocasião em diante fui procurando amar a outras mulheres gordas e saudáveis, ampliando essa experiência a homens com tais características que me parecessem simpáticos.

Aos poucos passei a incluir as pessoas que não me eram simpáticas e até algumas magras porque elas já eram tantas que se alguma morresse não me faria falta, mesmo que fosse minha mãe (Forghieri , 2007).

\section{0 saber básico}

Provavelmente em decorrência de meus "exercícios de amar as pessoas" adquiri o hábito de perceber nas pessoas algo que todos nós possuímos: nossos aspectos saudáveis; não num sentido apenas físico, aparente, e sim profundo, penetrando no seu íntimo, que nem sempre é aparente.

Adquiri também, o hábito de estar atenta às vivências, as minhas e as das pessoas com as quais me relaciono, e quando iniciei meus estudos em Psicologia e entrei em contato com a Fenomenologia, encontrei em Husserl $(1965,1986)$ e em Merleau-Ponty $(1971,1973)$ a idéia de que é da vivência imediata que surgem os nossos conhecimentos. Mas o processo de conhecimento não é solitário e estático, ele é também dinâmico e intersubjetivo; deve ser permanentemente ampliado ou contestado com novas vivências e articulado aos conhecimentos adquiridos pelas pessoas consideradas competentes em sua área científica.

É deste modo que cada um de nós adquire e desenvolve o que denomino de Saber Básico. Ele consiste no modo de pensar e de agir que surge e começa a se desenvolver a partir da infância. Podemos notá-lo, por exemplo, quando uma criança se recusa a vestir um agasalho porque não está com frio; ou não quer comer um alimento porque não gosta.

Entre minhas vivências infantis, o conhecimento mais significativo que adquiri foi a enorme importância do amor em nossa vida; e o tenho confirmado, cada vez mais no decorrer de minha existência. Nos estudos que tenho feito do fenomenólogo das relações, Martin Buber $(1977,1982)$, encontrei a confirmação desse conhecimento e também os seus fundamentos. Em Heidegger (1988) encontrei esclarecimentos sobre a angústia, tão profundamente vivida por mim na infância. Com os psiquiatras Binswanger (1965, 1973), Boss (1963, 1983), Minkowski (1982) e Van den Berg (1973), desenvolvi minhas idéias sobre a nossa vivência no mundo e seus vários aspectos, sobre as vivências do espaço, do tempo e da liberdade.

Menciono previamente esses autores fenomenológicos e algumas de suas influências em meu saber básico, pois entrelacei tão profundamente minhas idéias às suas, que muitas vezes não consigo distinguir se falo em meu próprio nome ou no deles. Por isso quero deixar claro que meu enfoque do ser humano pode não ser 
estritamente fenomenológico; talvez fosse melhor chamá-lo, como digo aos meus alunos, de yolandismo, para não comprometer a Fenomenologia.

\section{A personalidade e 0 adoecimento existencial}

O ser humano é um ser-no-mundo. Existe sempre em relação a algo ou a alguém; é desse modo que ocorrem suas vivências. Denomino de vivência o contato de cada um de nós com o mundo. Este se apresenta para nós em três aspectos: o circundante que abrange a natureza, o humano que é constituído dos seres humanos, e o próprio que é a relação da pessoa consigo mesma.

A vivência pode ser imediata ou racional; ela tem um significado para o indivíduo e vem sempre acompanhada de humor que se manifesta em sentimentos de grado ou de desagrado; estes podem ser muito leves, que quase não percebemos, ou tão intensos que chegam a nos arrebatar completamente.

O significado da vivência costuma variar de um indivíduo para outro. Assim, por exemplo, para uma jovem romântica ao contemplar uma frondosa paineira florida, esta lhe parecerá como um local agradável para estar com seu amado. Entretanto a mesma árvore, se for observada por um madeireiro ambicioso poderá lhe parecer um ótimo material para ser cortado e vendido por bom preço.

A vivência agradável facilita o seu significado, enquanto a desagradável o dificulta. Podemos observar isto quando vivenciamos uma situação que nos agrada; rapidamente a aceitamos e compreendemos. Entretanto se a situação nos é desagradável temos a tendência a evitá-la e a não compreender porque está nos acontecendo. Quando o desagrado é intenso percebemos com mais clareza a dificuldade para atribuirmos significado à situação. Assim, por exemplo, quando a pessoa precisa enfrentar o rompimento de um profundo relacionamento amoroso, feito pelo seu parceiro; nos primeiros momentos ela fica sem entender e sem aceitar este fato. É freqüente dizer: por quê? Eu não mereço... E enquanto não aceitar este fato como a sua realidade, não encontra significado para ele. Aceitar não quer dizer considerar agradável o que está acontecendo e sim considerar ser esta a sua realidade, para a qual pode mesmo não ser possível encontrar a sua causa. Em nossa existência há muitos mistérios que não conseguimos entender e que precisamos aceitar, para seguirmos em frente, partindo para outra de nossas inúmeras possibilidades de viver. Enquanto não aceitamos uma intensa contrariedade como inerente à nossa existência, ela pode passar a dominar toda a nossa vida, impedindo-nos de prosseguir em nosso amadurecimento. Há indivíduos, por exemplo, que devido à morte de uma pessoa muito querida passam o resto da vida tristes e deprimidas, como se estivessem parados em seu existir. E assim... adoecem existencialmente; pesquisas que realizei sobre vivências intensas de contrariedade e de bem estar confirmam estas formulações (Forghieri, 2004).

O adoecimento existencial pode acontecer também quando um indivíduo permanece exageradamente em vivências racionais; para tentar evitar vivências de contrariedade planeja todas as suas atividades e as segue a risca. E sua vida acaba se tornando monótona, sem acontecimentos novos, pois o raciocínio baseia-se no 
passado e desse modo o indivíduo dificulta ou até mesmo impede o surgimento de vivências imediatas agradáveis.

Entretanto precisamos nos arriscar, abrindo-nos ao futuro se quisermos amadurecer; é importante que consigamos manter um equilíbrio entre vivências racionais e imediatas. Estas poderão nos proporcionar tanto contrariedades como alegrias; de certo modo precisamos reduzir o medo de sofrer para que aprendamos a enfrentar o sofrimento, mas a ter também momentos de prazer. Viver entre alegrias e tristezas é um grande paradoxo de nossa existência (Forghieri, 2004).

\section{O Aconselhamento Terapêutico}

\section{0 amor e a angústia}

Ambos constituem os dois pólos básicos de nossa existência. O amor aqui é considerado como a plenitude do bem-estar; uma vivência de completa sintonia da pessoa em seu existir no mundo. Num sentido profundo o amor encontra-se enraizado na própria vida, tanto em seus aspectos materiais e naturais como humanos e espirituais. Este acontece, por exemplo, quando contemplo o entardecer e me sinto completamente envolvida, como se juntos constituíssemos uma totalidade, sinto-me em paz, acolhida no mundo. Posso também me sentir envolvida, sintonizada com meu cão de estimação; ao agradá-lo enquanto ele me corresponde, sinto que juntos partilhamos da vida. E o amor acontece com maior plenitude quando me relaciono com uma pessoa, e nos sintonizamos reciprocamente, nossos olhares se correspondem, nossas mãos se tocam e mesmo sem palavras nos sentimos mutuamente presentes, queridos e correspondidos. Mas o amor pode também se manifestar numa tênue vivência de bem-estar.

A angústia é a mais profunda e intensa contrariedade e distanciamento do mundo, em seus aspectos materiais, animais e humanos. Ela se encontra enraizada em nossa própria morte e se manifesta em nossos limites, nossas frustrações, nossa impotência diante de doenças, desastres, catástrofes da natureza, etc. Entretanto, a angústia pode se manifestar levemente, em tênue vivência de mal-estar.

\section{0 processo terapêutico}

O aconselhando, ao procurar um aconselhador, geralmente encontra-se aflito e/ou deprimido, angustiado, meio confuso, com grande dificuldade, ou sem conseguir aceitar e enfrentar as contrariedades, frustrações e conflitos de sua existência. Sente-se sozinho, com pouca ou nenhuma liberdade para entrar em sintonia em seu ser-no-mundo e abrir-se às suas múltiplas possibilidades. O fluxo de seu existir encontra-se encoberto pelas cinzas de seus sofrimentos, mesmo em ocasiões que poderiam lhe propiciar bem-estar.

Assim sendo, a primeira tarefa do aconselhador ou terapeuta é remover aquelas cinzas que estão encobrindo o fluxo do existir do aconselhando ou cliente para que ele seja estimulado a fluir. Para que isto aconteça é necessário que o 
aconselhador esteja plenamente presente ao aconselhando propiciando-lhe uma vivência imediata de bem-estar, na relação entre ambos.

Nisto consiste o envolvimento existencial no qual o terapeuta fica completamente aberto ao cliente sem qualquer defesa que possa afastá-los; torna-se uma pessoa presente ao cliente, um companheiro semelhante a ele naquilo que é comum a ambos: existir-no-mundo entre realizações e frustrações, possibilidades e limites, alegrias e sofrimentos. Em outras palavras, o terapeuta procura amar o cliente. Este, ao perceber a presença do terapeuta e ao perceber que consegue atingilo, mexer com ele, sente-se ativo e acompanhado, e adquire coragem para começar a aceitar e a enfrentar seus sofrimentos.

Conforme nota que o cliente percebe sua presença e se sente acompanhado, o terapeuta começa a conscientizar o cliente e a dialogar com ele a respeito do seu saber básico e de suas dificuldades. Nisto consiste o distanciamento reflexivo no qual o terapeuta atua como o profissional disposto a ajudar o cliente a enfrentar cada uma de suas dificuldades, aceitando-a e resolvendo-a, ou transcendendo-a partindo então para outras escolhas. O terapeuta inicia o distanciamento procurando propiciar ao cliente que ele se conscientize do seu próprio saber básico, para depois ir ajudando-o a ampliá-lo, através de hipóteses a serem examinadas por ambos. Estas só serão mantidas se o cliente as compreender e aceitar.

Embora descritos separadamente, para facilitar a sua descrição, o envolvimento existencial e o distanciamento reflexivo constituem a totalidade do processo terapêutico, não sendo separados, mas complementares e reversíveis um no outro. Cada um deles torna-se predominante a cada momento em que o terapeuta percebe que o cliente está necessitando de sua presença, ou está em condições de ter consciência de suas dificuldades.

Nesse envolver-se e distanciar-se, o principal objetivo do aconselhador ou terapeuta, não é atuar no sentido de descobrir e remover a psicopatologia do aconselhando e sim procurar - com ele-descobrir algum ou alguns de seus aspectos saudáveis, dos quais ele já se esqueceu, ou nem havia chegado a saber. Em outras palavras, o objetivo principal é possibilitar ao cliente vivenciar momentos agradáveis, viver melhor... ser feliz...

Minha longa experiência como aconselhadora tem evidenciado que isto é possível, apenas com alguns atendimentos. À medida que o cliente vai conseguindo descobrir e agir no sentido de atualizar e desenvolver algum de seus aspectos saudáveis, vai conseguindo vivenciar, cada vez mais, momentos agradáveis, e seus sintomas tendem a diminuir, ou a não incomodá-lo como antes.

Não quero com isso dizer que nós, seres humanos, consigamos ser, permanentemente contentes e felizes, pois não conseguimos evitar as frustrações e contrariedades. Porém, podemos aprender a enfrentá-las e superá-las, recuperando nosso bem-estar, para mais adiante perdê-lo e voltar a conquistá-lo, e assim sucessivamente, até o final de nossa existência. Este é o maior paradoxo de nosso existir: viver entre o amor e a angústia, a realização e a frustração, o bem-estar e a contrariedade. 
E para conseguirmos manter a periódica recuperação do bem estar é importante que consigamos alcançar e manter a nossa espiritualidade. Eu não saberia defini-la, mas vou tentar descrevê-la: é um modo de existir percebendo e sentindo que nós, seres humanos, somos companheiros em nossa difícil jornada neste mundo, que pode ser significativamente suavizada nos sofrimentos e intensificada nas alegrias quando nos solidarizamos com nossos semelhantes.

\section{Referências Bibliográficas}

Alexander, G.F. \& Selesnick, A. (1968). História da psiquiatria. São Paulo: Ibrasa. Binswanger, L. (1965). Being in the world. New York: Basic Books.

Binswanger, L. (1973). Articulos y conferéncias escogidas. Madrid: Gredos.

Boss, M. (1963). Psychoanalysis and daseisanalysis. New York: Basic Books.

Boss, M. (1983). Existential foundations of Medicine and Psychology. New York: Aronson. Buber, M. (1977). Eu e Tu. São Paulo: Cortez e Moraes.

Buber, M. (1982). Do diálogo e do dialógico. São Paulo: Perspectiva.

Forghieri, Y. (2004). Psicologia fenomenológica: fundamentos, método e pesquisas. São Paulo: Pioneira Thomson Learning.

Forghieri, Y. (2004). Saúde existencial: vivência a ser periodicamente reconquistada. Boletim da Academia Paulista de Psicologia, Ano XXIV, Vol.1, No. 4, p.46-57.

Forghieri, Y. (2007). Aconselhamento terapêutico: origem, fundamentos e prática. São Paulo: Thomson Learning.

Heidegger, M. (1988). Ser e tempo. Petrópolis: Vozes.

Husserl, E. (1965). A Filosofia como ciência de rigor. Coimbra: Atlântida.

Husserl, E. (1986). Ideas relativas a uma fenomenologia pura y una filosofia fenomenológica. México: Fundo de Cultura.

Merleau-Ponty, (1971). Fenomenologia da percepção. São Paulo: Freitas Bastos.

Merleau-Ponty, M. (1973). Ciências do homem e fenomenologia. São Paulo: Saraiva.

Minkowski, E. (1982). El tiempo vivido. México: Fondo de Cultura Económica.

Piñero, J.M. \& Meseguer, M. (1970). Neurosis y psiquiatria. Madrid: Epasa Calpe

Van den Berg, J.H. (1973). O Paciente psiquiátrico. São Paulo: Mestre Jou. 


\begin{abstract}
The Therapeutical Counseling, also called Psychological Counseling, consists of an interpersonal relationship of existential aid, whose origin retraces the Antiquity, in the "cure for the word" introduced and practiced by the philosopher Empedocles and adopted by other philosophers after it, and for doctors when these had appeared. It had fast evolution from century XX, mainly after each one of the great world-wide wars, when it passed to be practiced by many educational and professional people who orientates, and nurses, to take care of the existential necessity helping the numerous shaken people, for which the amount of psychiatrists and psychotherapists was not enough. From 1950 it was recognized for the scientific community as an efficient interpersonal therapeutical relationship, next, but different of the psychotherapy. It passed, then, to be influenced by some psychological approaches, like the phenomenological. Based on this, the beddings and the practical of Counseling are presented, that consists of two basic moments: the existential evolvement and the reflective distance, that are complementary and reciprocally reversible.
\end{abstract}

Key words: Therapeutical Counseling, Existential Aid, Phenomenological Approach, Human Existence.

Resumen: El Aconsejamiento Terapéutico, también llamado Aconsejamiento Psicológico, consiste en un relacionamiento interpersonal de ayuda existencial, cuyo origen se remonta a la Antigüedad, en la "cura por la palabra”, introducida y practicada por el filósofo Empédocles y adotada, más tarde, por otros filósofos y, cuando aparecieron, por los médicos. Tuvo una rápida evolución a partir del siglo XX, principalmente, después de cada una de las grandes guerras mundiales, cuando pasó a ser practicado por muchos orientadores educacionales profesionales y enfermeras para atender a las necesidades de socorrer a las numerosas personas abaladas existencialmente, para las cuales la cantidad de siquiatras y sicoterapeutas no era suficiente. A partir de 1950 fue reconocido por la comunidad científica como un eficiente relacionamiento interpersonal de ayuda terapéutica, próxima, pero diferente de la psicoterapia. Pasó, entonces, a ser influenciado por varias corrientes sicológicas, entre ellas, la fenomenológica. Con base en ella se presentan los fundamentos y la práctica del Aconsejamiento, que se constituye de dos momentos básicos: el envolvimiento existencial y el distanciamiento reflexivo, complementarios y recíprocamente reversibles.

Palabras-clave: Aconsejamiento Terapéutico, Enfermarse Existencialmente, Abordaje Fenomenológica, Existéncia Humana.

Yolanda Cintrão Forghieri é Professora Titular, Livre Docente e Doutora. Instituto de Psicologia da USP (Endereço para correspondência: Rua Estado de Israel 847 / 31 CEP 04022-002). 